argument as to whether some form of international organization for co-ordinating the work of national associations for the advancement of science and the national associations of science writers should be set up. Finally, however, a recommendation was adopted to the effect that it was undesirable at the present moment to establish an international organization for these purposes, but that Unesco should consider the possibility of forming a consultative committee to further co-operation between the various national associations if this should prove necessary.

Although the Conference produced no definite or positive conclusions, it was nevertheless valuable in showing that the problems of popularizing science vary greatly from country to country, and in bringing people together with similar interests from many countries.

T. A. Margerison

\section{ROYAL BOTANIC GARDENS, KEW}

\begin{abstract}
A REVIEW of all aspects of the work of the Royal Botanic Gardens, Kew, during 1954, is presented in the Kew Bulletin, No. 1, 1955. The past year has been one of sustained progress, but various problems of accommodation remain acutefor example, the Palm House, the Herbarium and Library-and are receiving close attention. The main activities of the Gardens, however, are being maintained with unimpaired vigour. It is impossible to touch on more than a few of these in this short article, but some idea of the nature and volume of the problems handled may be indicated by some selected references. Thus, the specimens received for the Herbarium, excluding those prepared at Kew from living material, amounted to 55.994; some 9,166 sheets were received on loan; 5,652 were sent on loan; 16,424 sheets were distributed as duplicates; and, in all, some 47,780 sheets were mounted (excluding algae, lichens, fungi and bryophyta, and specimens received already mounted). No fewer than 4,077 botanists paid visits during 1954, many of these being from overseas, attending the Eighth International Botanical Congress at Paris. Here, too, reference may be made to the fact that 2,635 inquiries and plant consignments were dealt with during the year.
\end{abstract}

As in previous years, important activities were the identification of economic plant products and the supplying of information on economic plants: for example, cinnamon, groundnuts, sesamum, raffia, balsa, senna, sansevieria, capers, opium poppy, aloes, patchouli, pepper, ginger, vanilla and cardamoms. In relation to the present high prices of tea and coffee, various inquiries as to the possibility of growing these crops in new areas received consideration.

For many years the Gardens have rendered an important service to scientific agriculture by maintaining the Quarantine House, the function of which is to prevent the spread of diseases and pests during the transference of economic plants from one part of the world to another. Thus, at the present time, varieties of cacao from the Imperial College of Tropical Agriculture, Trinidad, have occupied most of the available space during the year, these being the most promising of the Imperial College selections of Trinidad trees and some Amazonian forasteros originally collected on the Upper Amazon. Rooted cuttings from these plants have been suitably packed and sent by air to the West African Cacao Research Institute, Gold Coast, and to the Departments of Agriculture in Malaya, Ceylon and Fiji, and, with the exception of a consignment sent to Malaya, are reported to be growing successfully in their new environments. Material of Theobroma and the related genus Herrania, collected in Colombia in 1952 and sent to Kew via Trinidad, is now on its way to West Africa for the use of plant-breeders there. Various banana and cotton collections are also under sur. veillance in the Quarantine House.

A further service to countries of the British Commonwealth consists in obtaining plants of potential value. For example, young plants of ipecacuanha (Cephaelis ipecacuanha Rich.) have been sent to the Departments of Agriculture in Nigeria, British Honduras and Malaya for local trials.

Work of a rather different kind consists of research on the systematic anatomy of the Monocotyledons; notes on this important and extensive undertaking have appeared from time to time in these columns. Arrangements for the publication of this work in three volumes, of which the first will deal with the Gramineae, have now been made with the Clarendon Press, Oxford. A large number of routine inquiries, relating to miscellaneous botanical materials, including timbers, archæological specimens, and rubbed and powdered herbs, have been dealt with in the Jodrell Laboratory during the year. Among the more unusual samples were nylon bobbins examined on behalf of the Board of Customs and Excise, twigs of alleged apple trees, most of which proved to be plum suckers, submitted by the laboratory at New Scotland Yard, and unsatisfactory pick handles which were found not to have been made of the timber that had been specified.

The report also deals in some detail with the progress that has been made in the preparation of the several regional floras, and with other taxonomic studies, and the cultural work in the different sections of the Gardens is appropriately reviewed. A comprehensive list of publications and a staff list conclude this interesting and important publication.

\section{OPINIONS AND SOCIAL PRESSURE}

W HAT is the effect of the opinions of others on our own? How strong is the urge towards social conformity? An American psychologist, Solomon E. Asch, has approached these questions by means of unusual experiments. These, and his findings, have been described in the November issue of Scientific American, which contains a number of other articles of outstanding interest as follows : "Trenches of the Pacific", by R. L. Fisher and R. Revelle; "Synthetic Diamonds", by P. W. Bridgman; "Radiation and Human Mutation", by H. J. Muller; "Empty" Space", by H. C. van de Hulst ; "What makes Leaves Fall ?", by W. P. Jacobs; "Etruscan Metallurgy", by A. N. Modora; "Too Many Deer", by A. S. Leopold*.

Dr. Asch's investigations were guided by certain underlying assumptions, which to-day are common currency and account for much that is thought and said about the operations of propaganda and public opinion. The assumptions are that people submit uncritically and painlessly to external manipulations by suggestion or prestige, and that any given idea or * Scientific American, 193 (November 1955), 2 West 45th Street, New York. 50 cents. 
value can be 'sold' or 'unsold' without reference to its merits. Asch has described his experiments as follows.

A group of seven to nine young men, all college students, are assembled in a classroom for a "psychological experiment" in visual judgment. The experimenter informs them that they will be comparing the lengths of lines. He shows two large white cards. On one is a single vertical black line--the standard length of which is to be matched. On the other eard are three vertical lines of various lengths. The subjects are to choose the one that is of the same length as the line on the other card. One of the three actually is of the same length; the other two are substantially different, the difference ranging from three-quarters of an inch to an inch and threequarters.

The subjects announce their answers in the order in which they have been seated in the room, and on the first round every person chooses the same matching line. Then a second set of cards is exposed; again the group is unanimous. The members appear ready to endure politely another boring experiment. On the third trial there is an unexpected disturbance. One person near the end of the group disagrees with all the others in his selection of the matching line. He looks surprised, indeed incredulous, about the disagreement. On the following trial he disagrees again, while the others remain unanimous in their choice. The dissenter becomes more and more worried and hesitant as the disagreement continues in succeeding trials; he may pause before announcing his answer and speak in a low voice, or he may smile in an embarrassed way.

What the dissenter does not know is that all the other members of the group were instructed by the experimenter beforehand to give incorrect answers in unanimity at certain points. The single individual who is not a party to this pre-arrangement is the focal subject of the experiment. He is placed in a position in which, while he is actually giving the correct answers, he finds himself unexpectedly in a minority of one, opposed by a unanimous and arbitrary majority with respect to a clear and simple fact. Upon him are brought to bear two opposed forces : the evidence of his senses and the unanimous opinion of a group of his peers. Also, he must declare his judgments in public, before a majority which has also stated its position publicly.

The instructed majority occasionally reports correctly in order to reduce the possibility that the naïve subject will suspect collusion against him. There are eighteen trials in each series, and on twelve of these the majority responds erroneously.

How do people respond to group pressure in this situation. First, there are the statistical results of a series in which a total of 123 subjects from three institutions of higher learning were placed in the minority situation described above.

Of the 123 put to the test, a considerable percentage yielded to the majority. Whereas in ordinary circumstances individuals matching the lines will make mistakes less than I per cent of the time, under group pressure the minority subjects swung to acceptance of the misleading majority's wrong judgments in $36 \cdot 8$ per cent of the selections.

Individuals differed in response. At one extreme about one-quarter of the subjects were completely independent and never agreed with the erroneous judgments of the majority. At the other extreme, some individuals went with the majority nearly all the time. The performances of individuals in this experiment tend to be highly consistent. Those who strike out on the path of independence do not, as a rule, succumb to the majority even over an extended series of trials, while those who choose the path of compliance are unable to free themselves as the ordeal is prolonged.

The reasons for the startling individual differences have not yet been investigated in detail. At this point only some tentative generalizations from talks with the subjects, each of whom was interviewed at the end of the experiment, can be reported. Among the independent individuals were many who held fast because of staunch confidence in their own judgment. The most significant fact about them was not absence of responsiveness to the majority but a capacity to recover from doubt and to re-establish their equilibrium.

Many of the individuals suspected that the majority were 'sheep' following the first responder, or that the majority were victims of an optical illusion; nevertheless, these suspicions failed to free them at the moment of decision. More disquieting were the reactions of subjects who construed their difference from the majority as a sign of some general deficiency in themselves. which at all costs they must hide.

Which aspect of the influence of a majority is more important-the size of the majority or its unanimity ? The experiment was modified to examine this question. In one series the size of the opposition was varied from one to fifteen persons. The results showed a clear trend. When a subject was confronted with only a single individual who contradicted his answers, he was swayed little: he continued to answer independently and correctly in nearly all trials. When the opposition was increased to two, the pressure became substantial : minority subjects now accepted the wrong answer 13.6 per cent of the time. Under the pressure of a majority of three, the subjects' errors jumped to $31 \cdot 8$ per cent. But further increases in the size of the majority apparently did not increase the weight of the pressure substantially. Clearly the size of the opposition is important only up to a point.

Disturbance of the majority's unanimity had a striking effect. In this experiment the subject was given the support of a truthful partner-either another individual who did not know of the prearranged agreement among the rest of the group, or a person who was instructed to give correct answers throughout.

The presence of a supporting partner depleted the majority of much of its power. Its pressure on the dissenting individual was reduced to one-fourth. Most interesting were the reactions to the partner. Generally the feeling toward him was one of warmth and closeness; he was credited with inspiring confidence.

Was the partner's effect a consequence of his dissent, or was it related to his accuracy? There was now introduced into the experimental group a person who was instructed to dissent from the majority but also to disagree with the subject.

Again the results are clear. When a moderate dissenter is present, the effect of the majority on the subject decreases by approximately one-third, and extremes of yielding disappear. Moreover, most of the errors the subjects make are moderate. To this extent the subjects broke away from the majority even while bending to it. 
On the other hand, when the dissenter always chose the line that was more flagrantly different from the standard, the results were of quite a different kind. The extremist dissenter produced a remarkable freeing of the subjects ; their errors dropped to only 9 per cent. Furthermore, all the errors were of the moderate variety. It was concluded that dissent per se increased independence and moderated the errors that occurred, and that the direction of dissent exerted consistent effects.

\section{SCIENTIFIC EXPLORATION OF THE BELGIAN AFRICAN NATIONAL PARK OF THE GARAMBA}

\section{By Dr. TRACY PHILIPPS}

$\mathrm{T}$ EN years before the Second World War, King Albert of the Belgians founded the Belgian African National Parks and the National Parks Institute in Brussels for their scientific study; his scientific adviser was Dr. Victor van Straelen, who was until 1954 director of the Royal Institute of Natural Sciences. Dr. van Straelen is president of the National Parks Institute, where he carries out with foresight and energy the founder's purpose, and to whom the preliminary report of the Garamba expedition is dedicated by its members. Nominated by the King of the Belgians as British member of the Institute, I have for my five-year term taken part in the scientific administration of the Belgian African National Parks; the continuing British members are the Hon. Sir Evelyn Baring, Lord William Percy and Lord Willingdon.

The conservation of natural resources, including the recording of their inter-relation, is the more static of the Institute's two main objectives. In the realm of the natural sciences, the Institute's more dynamic part is for the improving of natural knowledge of how to reconstitute Nature's ill-used or over-used forces, and how to re-deploy them by now methods towards "delivering mankind from the bondage of ignorance" of himself and his surroundings.

No organization offers better opportunity than the Belgian African National Parks for uninhibited observation of natural surroundings, of what grows there and of what lives there, inter-related and influenced by the total environment. These reserves were most carefully chosen at the conjunction of great zoological and botanical zones, and of the meeting places of three main atmospheric currents. Botanically, the Garamba Reserve lies within Engler's Sudanic province, which extends roughly from the Senegal River to the foot of the Ethiopian plateau. The Institute's programme aims at establishing a scientific inventory of the fauna and flora of the reserves of which the Government has confided to it the administration. Thanks to the work already done on this plan, it can be said that the areas occupied by the Institute's four national parks between the Sudan and Rhodesia have become scientifically the best-known part of the African tropics. Only the most careful and systematic exploration enabled these results to be reached, and elements of remarkable interest to be placed at the disposal of organized science. Among the publications issued by the Brussels Institute during the past eight years there can be counted 1,334 new zoological species. These are headed by 561 Coleoptera. From the material collected by the Institute's scientific missions, sixty new botanical species have also been described.

Recently, an important exploration and inventory have been made in the National Park of the Garamba, which lies along the north-western section of the Congo-Nile Divide bordering the Nilotic Sudan. The Garamba is situated on the confines of two great bio-geographic areas, the Guinean and the Sudanic. This recent exploration has been working on a plan differing from its predecessors in the other park reserves. The latter were virtually confined to the collection of zoological and botanical specimens. The Garamba expedition's programme set out to determine all the characteristics of the biological environment, including climate and soil, and then to study the distribution of animals and plants in relation to these conditions. The insect collection alone of the expedition amounts to some 1,500,000 specimens. The number is considerable in view of the sum of the work entailed in the preparation of this fragile and perishable material, which cannot be ready for study before 1956. It will have cost five years in mounting, in the ecological recording of all the conditions surrounding each specimen, and in labelling.

Competent study of collections of this magnitude, essential for serious knowledge of flora and of fauna, present great difficulties due to lack of specialists in various branches of zoology. Thus, several families of insects collected in the Albert National Park (between the Lakes Kivr and Albert, and including Mount Ruwenzori) during the exploration of 1933-35 have not yet been examined for lack of available specialists. The size of the collections from the Belgian African National Parks often constitutes a big problem for the scientist who has to examine them. Thus, an American specialist has found himself charged with the examination of 170,000 specimens of Chloropidae, a little fly of which the larvæ of some species live in grass thatch or as parasites on non-vertebrate animals.

It is difficult as yet to appreciate the full value of the results of the recent exploration of the Garamba Reserve. A complete abstract of the observations and collections will first be essential to allow of any general conclusion. The botanical specimens being studied show very numerous species new to the Congo, and one family new to science. The zoological collections from the Garamba include 46,776 vertebrates, of which 2,914 are mammals, 3,122 birds, 4,641 fish, 34,511 frogs, 1,588 reptiles, and a number of albino bats. One bio-geographical discovery has, however, been made. It has long been observed that there is considerable similarity between the fish in the basins of the Nile and of the Congo, without there being any obvious present physical connexion. The Garamba expedition has now found, on the northern border of the Rescrve, a marsh situated in a gap in the north-western section of the Congo-Nile divide ; this marsh overflows in the rainy season both southward to the Congo towards the Atlantic and simultaneously northward into the Mediterranean basin through the Nile.

Henri de Saeger, who organized and led the Garamba exploration, feels that there is good reason for believing that the results will be found to have brought to science an exceptionally rich contribution. 